\title{
NINE WHOOPING CRANES
}

KEITH BARR, 40 Richardson Crescent, Regina, Saskatchewan. S4S 4J3

A few years ago, on the front page of the local newspaper, there was a picture of several Whooping Cranes. The photo credits were given to the Museum of Natural History. I phoned the museum and got the location of the cranes.

My teenage son and I travelled to the general area where the cranes should be. We were fortunate to spot three of them flying overhead. There were two adults and one juvenile. We followed them in the car as they flew south, thinking that this would be the first and last we would see of them as they migrated south. We were lucky to have seen our first Whooping Cranes. If we had been a few minutes later we would have missed them.

But wait ... they turn west and land in a stubble field about a quarter of a mile away. We take a couple of pictures of them and they fly over a low hill. We follow them and much to our surprise we see nine Whooping Cranes. This is our lucky day! Here are about 14 percent of the world's population of wild Whooping Cranes right before our eyes. The cranes are wading in a large slough. There appear to be three family groups, six adults and three juveniles. We use an old fallen down grain bin as a blind. It is about 400 feet from the slough. We take several pictures of the cranes. The light is fading. We will come back tomorrow and build a blind at the edge of the slough and get some better pictures.

On arriving back at the slough the next morning, we can see the cranes about a mile away feeding in the stubble. Walking down to the slough, we see a pile of telephone pole cross arms. These would make a nice base for our blind. We make several trips carrying these cross arms to the slough. The blind is finished. All we have to do is wait for the cranes to come back.

\section{BANG! BANG! BANG! DUCK HUNTERS!!}

We look to where the cranes are. They are flying. Well, that is the last we will see of those Whooping Cranes. We take the blind apart and carry the cross arms back and are just coming back to pick up the cameras when FLAP! FLAP! FLAP! We look up ... the cranes are right overhead. We drop to the ground, trying to make ourselves small and inconspicuous. This is near impossible for six-foot men to do! The cranes land right in front of where the blind had been. We are about 100 feet away. I am sure that they know that we are there. They do a bit of dance for us as we take pictures. They then fly about a quarter of a mile away and start to feed in the stubble field.

We go to the edge of the slough and hide in the bullrushes. We can see the entire slough. The cranes return to the slough after about a half 


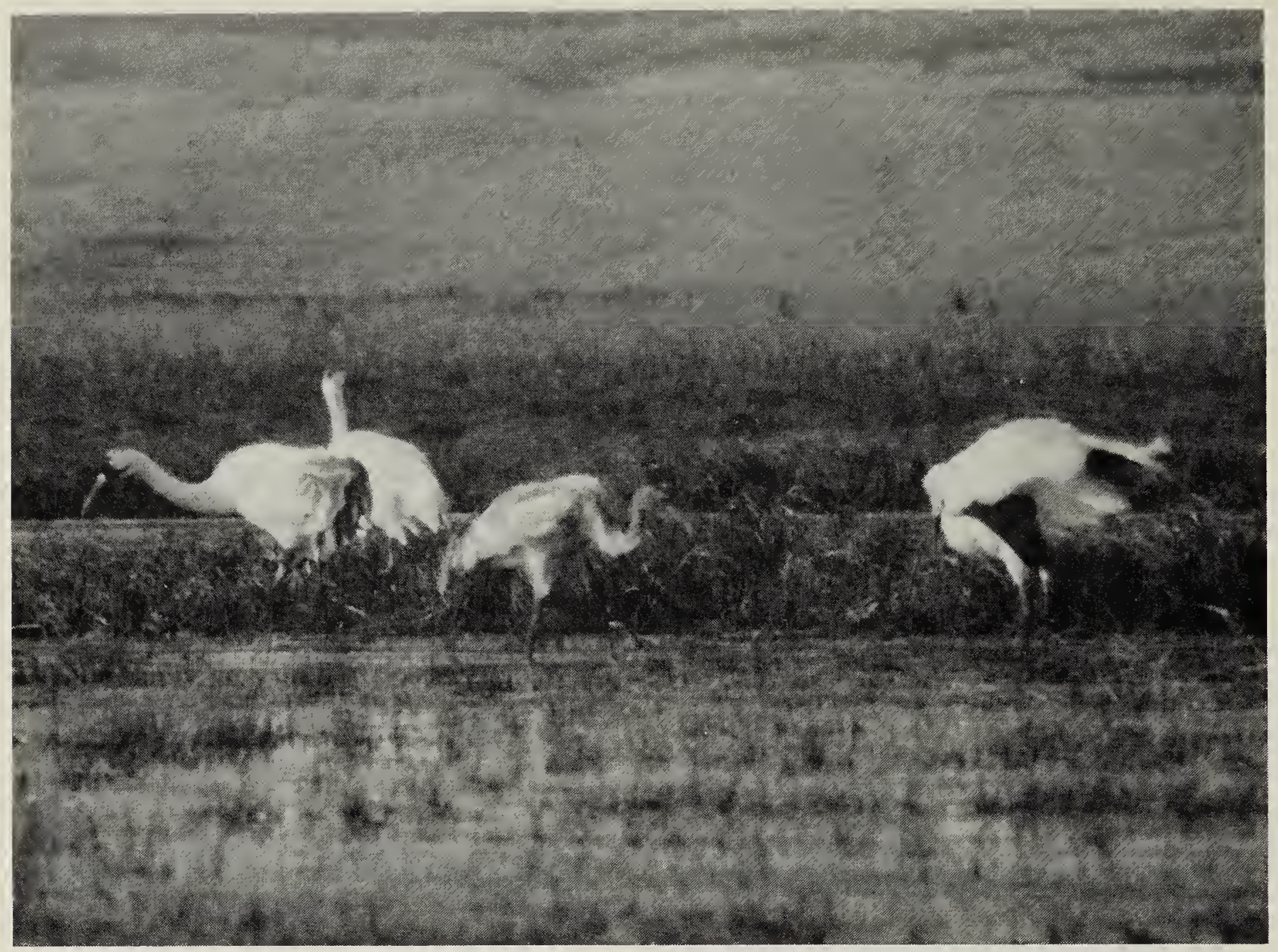

Whooping Cranes near Regina.

Keith Barr

hour. We take pictures and watch them for a couple of hours.

We notice a small yellow car approach the slough at the far end. Two hunters get out with their guns and approach the slough. The only things on the slough are one coot and the nine Whooping Cranes. The hunters get back into the car and drive to the area where the cranes are. They are on the opposite side of the slough from us. They stop the car and get out with their shotguns. They carry their guns across their chests. They want action and are ready for it. They approach the cranes. My God, what do we do? Jump up and scare the cranes? No, if we do that, they might fly right over the hunters. Should we just yell? I don't know what to do. The cranes see the hunters approaching, so they regally walk for a short distance and take flight. The hunters do not raise their guns. Do they finally realize what these magnificent birds are? I hope this is the reason. The hunters return to their car and drive away. My son and I run back to our car, which is about half a mile away. We go in search of the hunters but cannot find them.

A somewhat more amusing incident happened to this same group of Whooping Cranes. I do not recall who told me about this incident, but he was sitting in his car watching the cranes on the slough when he noticed a car racing towards the slough. As the car draws near, the cranes lift off. The driver of the car slams on the brakes, jumps with what appears to be a Brownie Hawkeye camera and takes a picture of the departing cranes.

I guess this is the method you have to use if you don't have a telephoto lens! 